\title{
Immobilized carbon nanofibers as industrial catalyst for ODH reactions
}

\author{
J.J. Delgado ${ }^{1}$, D.S. Su ${ }^{1}$, G. Rebmann ${ }^{2}$, N. Keller ${ }^{2}$, A. Gajovic ${ }^{3}$, R. Schlögl ${ }^{1}$ \\ ${ }^{1}$ Inorganic Chemistry Department, Fritz Haber Institute of the Max Planck Society, Faradayweg 4-6, 14195 Berlin, \\ Germany. \\ ${ }^{2}$ Laboratoire des Matériaux, Surface et Procédés pour la Catalyse, UMR 7515 CNRS, ECPM, Louis Pasteur University, \\ 25 rue Becquerel, 67087 Strasbourg Cedex 2, France \\ .$^{3}$ Division of Materials Physics Rudjer Boskovic Institute, Bijenicka 54, HR-10002 Zagreb, Croatia. \\ * corresponding author: Tel. +49 308413 5406, Fax.+4930841344 05, E-mail. dangsheng@fhi-berlin.mpg.de
}

\begin{abstract}
Carbon nanofibers have been immobilized onto carbon felt as the first step for their industrial application in Oxidative DeHydrogenation (ODH) reactions, exhibiting a stable performance with a high selectivity to styrene in the ODH of ethyl benzene at temperatures around $300 \mathrm{~K}$ lower than the actual industrial process, and inhibiting the problem that loose small particle as CNFs shows for being used as catalyst for fixed-bed reactors.
\end{abstract}

Keywords: Catalyst, carbon composites, carbon fibers, catalytic activity, immobilized carbon nanofibers.

Nanocarbons show promising performance in the oxidative dehydrogenation (ODH) of ethylbenzene (EB) $[1-4]$. However, the fine powder nature of nanocarbons, including onion-like carbons, carbon nanotubes, and nanofibers (CNFs), is highly detrimental to their use in fixed-bed reactors. Fine powders introduce large pressure drops and can lead to moving-bed phenomena. In addition, health concerns demand fixation of nanoparticles in applications with gas streams. Post-synthesis compaction is not desirable, because it changes the chemical properties of the nanocarbon materials and inhibits diffusion of reactants and products inside the compacted material.

Here we report on the catalytic performance and stability of CNFs anchored onto a macroscopic felt support for the ODH of EB to styrene (ST). The graphite felt has an open structure formed by a homogeneous network of carbon filaments and a higher thermal conductivity than oxide catalysts or supports. Graphite felt has a higher resistance to combustion than other catalyst supports, such as activated carbon [5]. The composite material thus obtained combines the properties of the nanostructured carbon and the advantages of the macrostructured graphite felt host, making it a stable catalyst and preventing the occurrence of hot spots and pressure drop. Using a graphite material as host structure also maintains continuity of the carbon's chemical properties. Preliminary studies indicate that this kind of material is active for the ODH of EB [6]. We present here, as the first step in industrializing the process for ST production, the loading effects of CNFs on graphite felt, the long-term stability of the composite and the microstructure of the composite before and after reaction studied by SEM, TEM, and Raman spectroscopy.

The nanocarbon composite was synthesized as described previously [7]. Nonporous graphite felts (Carbone Lorraine), were used as host structure, consisting of a network of entangled graphite microfibers with an average diameter of 10-18 $\mu \mathrm{m}$ (Fig. 1a) and lengths up to several tens of millimeters. Nickel $(1 \mathrm{wt} \%)$ was deposited by incipient wetness impregnation, and CNFs were produced at $973 \mathrm{~K}$ by catalytic chemical vapor decomposition (CCVD) using an ethane/hydrogen mixture (molar ratio of 1:5) after reduction of the nickel precursor at $673 \mathrm{~K}$. Various synthesis times were used to elucidate the effect of CNF loading on ODH catalytic performance. The catalytic tests were carried out at $673 \mathrm{~K}$ using $120 \mathrm{mg}$ of catalyst. An EB partial pressure of $2160 \mathrm{~Pa}$ (i.e., 2 vol\%) and a liquid hourly space velocity (LHSV) of $0.05 \mathrm{~h}^{-1}$ (i.e., a total flow of $10 \mathrm{ml} \mathrm{min}^{-1}$ ) were used. The oxygen:EB ratio was 5:1. The reactants and products were analyzed by an on-line Varian 3800 gas chromatograph. An EB <1\% was obtained for a blind test. Note that no steam was added as it is necessary in the actual industrial process. 


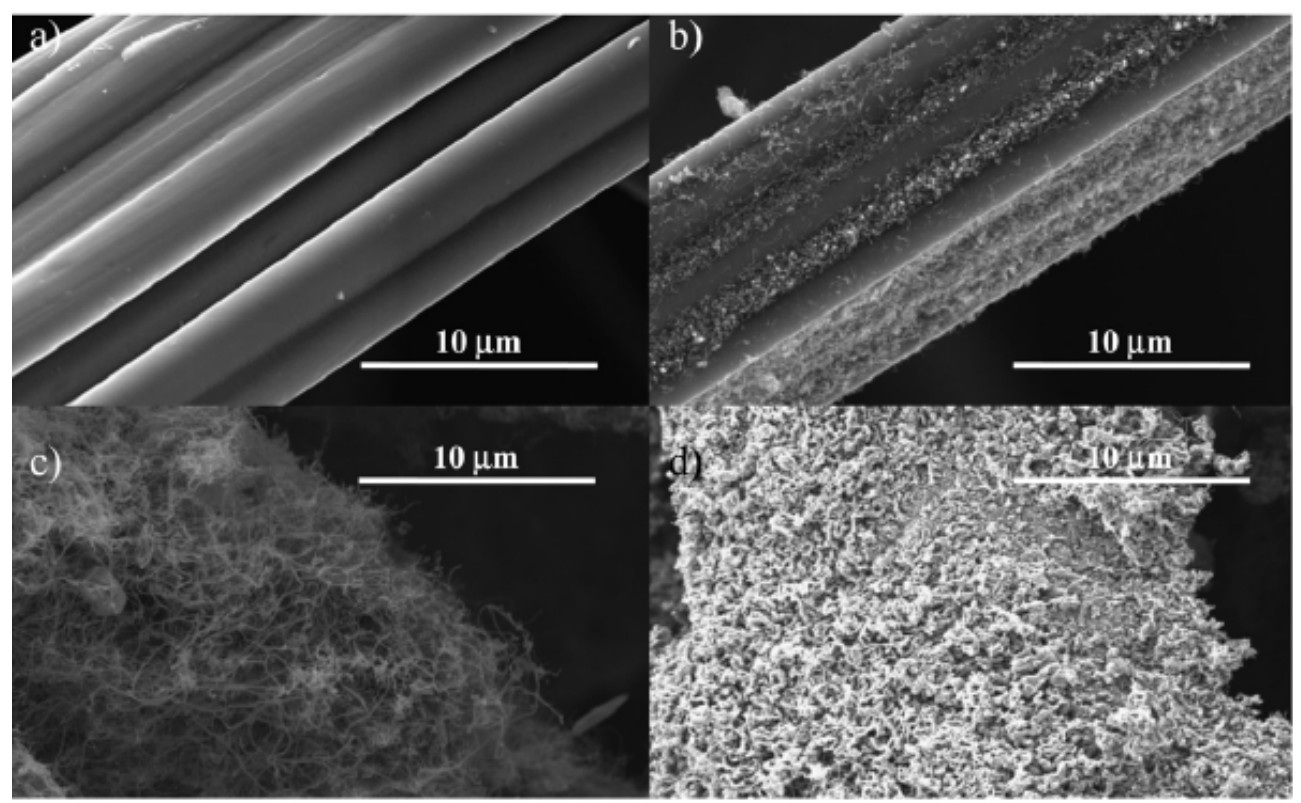

Fig. 1. SEM images of the initial graphite microfiber (a) and the catalyst obtained after 0.5 (b), 1.5 (c) and $2 \mathrm{~h}$ (d) of CCVD.

Table 1

Evolution of the weight, CNF loading and surface area with the CCVD time

\begin{tabular}{cclll}
\hline Sample & $\begin{array}{c}\text { CCVD } \\
\text { time }\end{array}$ & $\begin{array}{l}\text { Weight } \\
\text { change }(\%)\end{array}$ & $\begin{array}{l}\text { CNF loading } \\
(\mathrm{wt} \%)\end{array}$ & $\begin{array}{c}\mathrm{S}_{\mathrm{BET}} \\
\left(\mathrm{m}^{2} \cdot \mathrm{g}^{-1}\right)\end{array}$ \\
\hline Initial felt & $0 \mathrm{~h}$ & -- & -- & $<1$ \\
A & $0.5 \mathrm{~h}$ & 113 & 11.5 & $23.2 \pm 0.2$ \\
B & $1.5 \mathrm{~h}$ & 170 & 41.2 & $52.4 \pm 0.4$ \\
C & $2.0 \mathrm{~h}$ & 190 & 47.4 & $61.5 \pm 0.3$ \\
\hline
\end{tabular}

Fig. 1 shows images of the initial graphite felt (a) and different catalysts obtained after $0.5 \mathrm{~h} \mathrm{(b)}$ and $1.5 \mathrm{~h}$ (c) of CCVD. The initial felt consists of non-porous fibers. After $0.5 \mathrm{~h}$ growth time, anchored CNFs partly cover the felt surface. High-resolution SEM (Fig. 2a) shows the strong CNF-fiber interaction. The CNFs progressively cover the felt surface, with complete coverage achieved in $2 \mathrm{~h}$. Fig. $2 \mathrm{~b}$ shows that the CNFs have a herringbone structure, exposing an abundance of prismatic faces to the gas phase, as required for the formation of oxygen functional groups, which are necessary for the ODH reactions $[1,2,8]$. SEM and TEM show that the CNFs typically do not have a channel parallel to the growth axis. This can be explained by the carbon diffusion inside of the metal particles [9].

The increase in weight observed after CCVD, the CNF loading, and the surface area of the study samples are summarized in Table 1. The synthesis was totally selective toward CNFs; SEM and TEM detected no carbon nanoparticles or amorphous carbon. Note that the initial surface area of the graphite felt is $<1 \mathrm{~m}^{-1} \mathrm{~g}^{-1}$ and increases with the CNF content to $61.5 \mathrm{~m}^{2} \mathrm{~g}^{-1}$.

The large void volume between each CNF, shown in Fig. 1c allows the performance of gas-phase applications without the usual problems associated with nanomaterial powders, such as large pressure drops. The fixation of CNF onto a compact carbon support also prevents moving-bed phenomena in fixed-bed tubular reactors.

Fig. 3 shows catalytic performance as a function of time for the obtained samples. The initial felt without supported nickel was not active due to the low surface area. All of the tested composite materials were active at $673 \mathrm{~K}$, with the activity increasing with CNF loading. The selectivity of ODH reactions usually decreases significantly with increasing conversion [10]. However, the selectivity of all tested samples remained nearly constant at around $75 \%$. This may be related to the large void volume of the composite available for the gas stream, avoiding local transport limitations and hot spots.

Keep in mind that Ni loading decreases with CNF content, but the activity increases with CNF content and not with the metal content. The Ni loadings for samples A, B, and C were 0.9, 0.6, and 0.5, respectively. For sample $\mathrm{C}$, most of the $\mathrm{Ni}$ particles were encapsulated by carbon and did not contribute to the catalytic activity. Thus, there is no correlation between Ni content and catalytic activity.

Tests of catalytic performance for 1 week on stream indicated that the catalysts were stable under the operating conditions despite the presence of molecular oxygen (Fig. 3, inset). The carbon balance, including $\mathrm{CO}$ and $\mathrm{CO} 2$, was close to $99.5 \pm 3 \%$, demonstrating the stability of the catalyst under reaction conditions. Fig. 4 shows that the microstructure of CNFs (a) and the macrostructure of the composite (b) remained unchanged after reaction. This result is consistent with previous studies demonstrating high stability of the graphite-like structures under operation conditions [1-5]. 


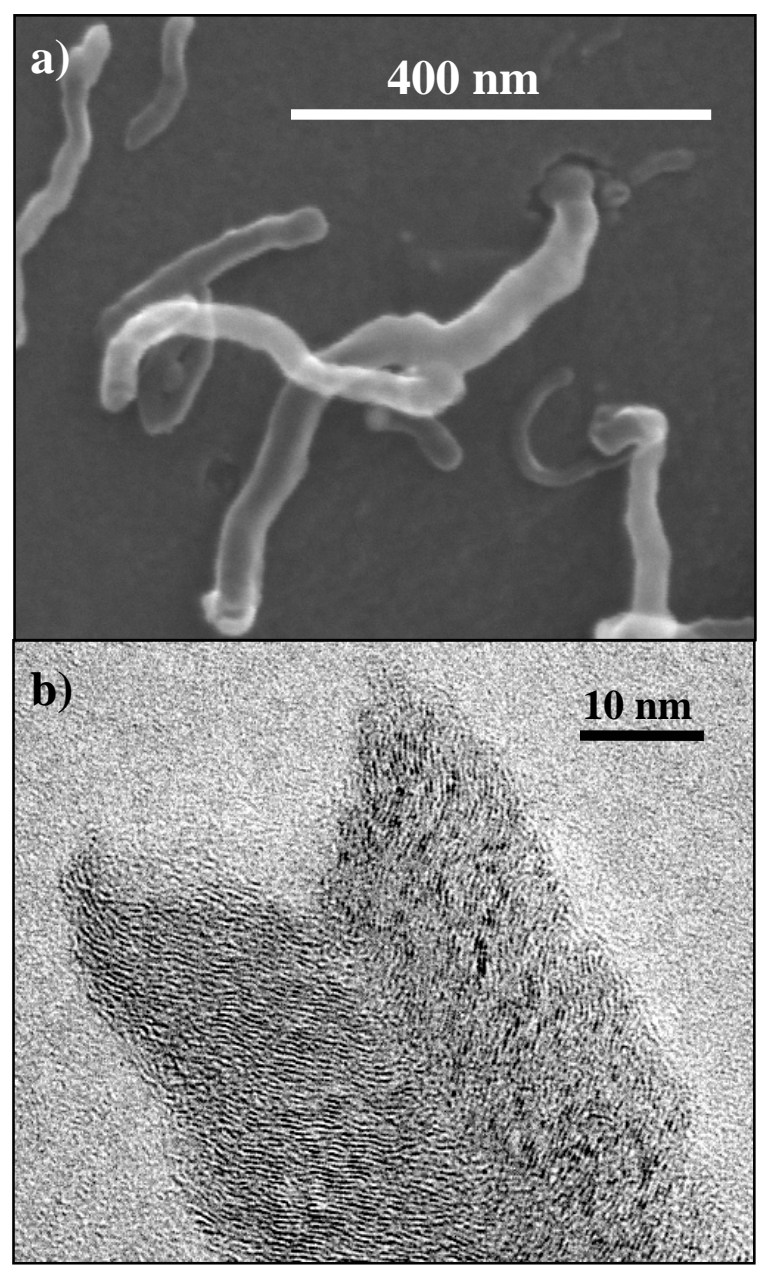

Fig. 2. SEM images of sample A showing CNFs anchored in the felt (a) and TEM of a typical CNF (b).

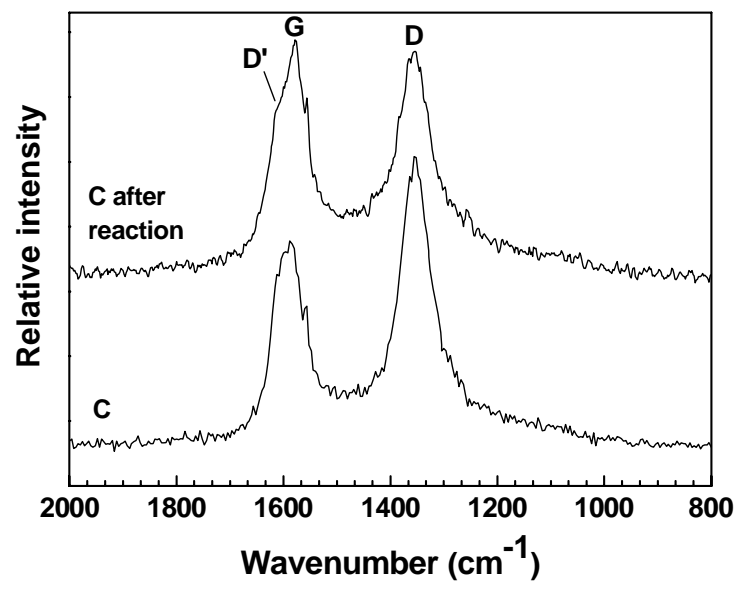

Fig. 3. EB conversion $\left(\boldsymbol{C}_{\mathrm{EB}}\right.$, filled) and selectivity ( $\boldsymbol{S}_{\mathrm{ST}}$, empty) as a function of time on stream obtained on different composites: A $(\boldsymbol{\Delta}), \mathrm{B}(\boldsymbol{\bullet})$ and $\mathrm{C}(\boldsymbol{\bullet})$. The inset figure shows a long term experiment using the sample $\mathrm{C}$.

Fig. 5 displays the Raman spectra of sample $\mathrm{C}$ before and after reaction. The Raman bands characteristic for

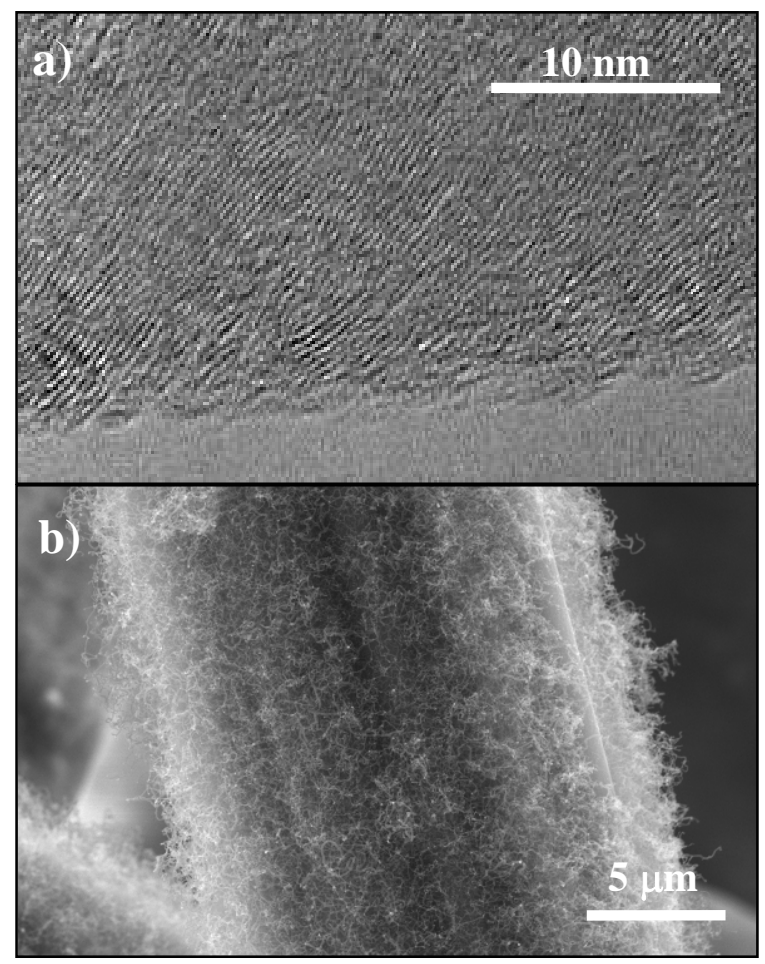

Fig. 4. TEM (a) and SEM (b) images of sample A after reaction.

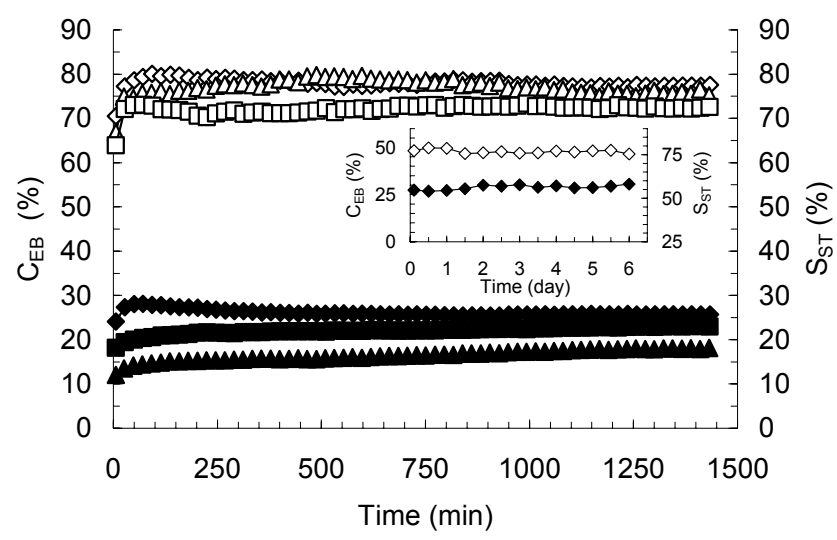

Fig. 5. Raman spectra of sample grown for $2 \mathrm{~h}$ (C) before and after reactionat $673 \mathrm{~K}$.

disordered (D: $1318 \mathrm{~cm}^{-1}$, and D_: $1602 \mathrm{~cm}^{-1}$ ) and ordered (G: $1573 \mathrm{~cm}^{-1}$ ) $s p^{2}$ sites are seen [2,11]. A small shoulder appears at $1556 \mathrm{~cm}^{-1}$ due to atmospheric oxygen in the cell. The intensity ratio of the $\mathrm{G}$ and $\mathrm{D}$ band, $I(\mathrm{D}) / \mathrm{I}(\mathrm{G})$, gives a qualitative description of the order. In graphite, $I(\mathrm{D}) / I(\mathrm{G})$ ratio decreases with increasing order [12]. The $I \quad$ (D)/I (G) ratio of sample $\mathrm{C}$ decreased from 1.36 before the reaction to 0.97 after the reaction. This dramatic decrease can be explained by the improved structure of the CNFs annealed during the time on stream in the reaction. This could be the reason for the longterm stability of the composite. This result is in agreement 


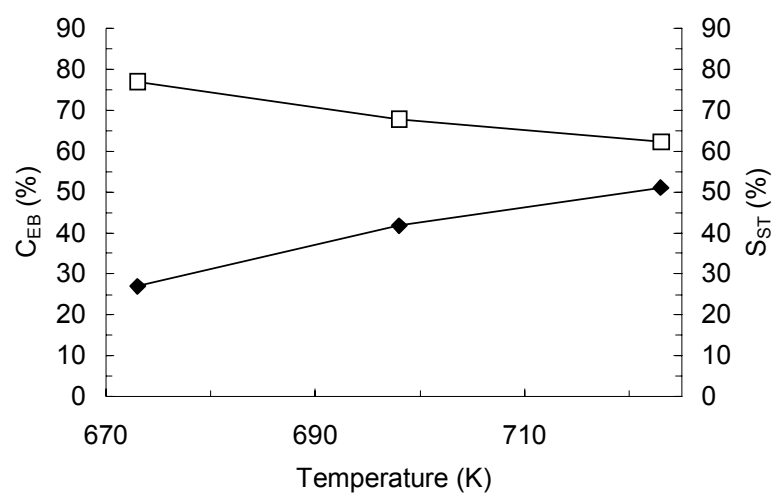

Fig. 6. EB conversion (CEB, filled) and selectivity (SST, empty)

with the results of the HRTEM images of the used sample (Fig. 4), revealing more ordered graphitic structure compared with that in the fresh sample.

It is worth noting that within the variation of the reaction conditions, no pressure drop occurred. This strongly differs from the large pressure drop observed in similar reaction conditions when the reaction was performed on nanocarbon powders [13].

Fig. 6 shows the catalytic activity and selectivity during the steady period of sample $\mathrm{C}$ at different temperatures. The EB conversion increased with slight increases in the reaction temperature; however, the selectivity decreased. The observed increase of $\mathrm{CO}$ and $\mathrm{CO}_{2}$ in the product indicates that the reaction at high temperature favors the total oxidation of EB.

To summarize, CNFs can be efficiently immobilized onto a graphite felt by supporting nickel and subsequent CCVD at $700{ }^{\circ} \mathrm{C}$ using a mixture of ethane and hydrogen. The CNF content can be easily controlled by the timing of the CCVD step. The resulting composites combine the property of the CNFs and the macroscopic features of the graphite felt host, thus avoiding limitations due to the finepowder form of the primary nanocarbon structure. The activity of the catalyst increased with increasing CNF content. The immobilization of efficient nanocarbon materials opens new routes for dehydrogenation reactions involving hydrocarbons as a general alternative to endothermic and thermodynamically limited direct dehydrogenation reactions. Our study indicates that high performance with good selectivity can be achieved working with high CNF loadings at low temperatures. The yield of $32 \%$ reported here is a promising indication for industrial applications, taking into account the absence of auxiliary stream and the much lower reaction temperature and the subsequent energy savings.

\section{Acknowledgments}

This work was funded by the European Union FP6 program (CANAPE project 500096).

\section{References}

[1] G. Mestl, N.I. Maksimova, N. Keller, V.V. Roddatis, R. Schlögl, Angew. Chem. Int. Ed. 40 (11) (2001) 2066-2068. [2] N. Keller, N.I. Maksimova, V.V. Roddatis, M. Schur, G. Mestl, Y.V. Butenko, V.L. Kuznetsov, R. Schlögl, Angew. Chem. Int. Ed. 41 (11) (2002) 1885-1888.

[3] D.S. Su, N.I. Maksimova, J.J. Delgado, N. Keller, G. Mestl, M.J. Ledoux, R. Schlögl, Catal. Today 102-103 (2005) 110-114.

[4] M.F.R. Pereira, J.L. Figueiredo, J.J.M. Órfão, P. Serp, P. Kalck, Y. Kihn, Carbon 42 (14) (2004) 2807-2813.

[5] M.F.R. Pereira, J.J.M. Orfao, J.L. Figueiredo, Appl. Catal. A Gen. 218 (1-2) (2001) 307-318.

[6] J.J. Delgado, R. Vieira, G. Rebmann, D.S. Su, N. Keller, M.J. Ledoux, R. Schlögl, Carbon 44 (2006) 809-812.

[7] R. Vieira, C. Pham-Huu, N. Keller, M.J. Ledoux, Chem. Commun. (2002) 954-955.

[8] J.A. Maciá-Agulló, D. Cazorla-Amorós, A. LinaresSolano, U.Wild, D.S. Su, R. Schlögl, Catal. Today 102-103 (2005) 248-253.

[9] K.P. De Jong, J.W. Geus, Catal. Rev.-Sci. Eng. 42 (4) (2000) 481-510.

[10] G. Ertl, H. Knözinger, J. Weitkamp (Eds.), Handbook of Heterogeneous Catalysis, Wiley-VCH, New York, 1997.

[11] J. Robertson, Mat. Sci. Eng. R 37 (2002) 129-281.

[12] K.W.R. Gilkes, S. Prawer, K.W. Nugent, J. Robertson, H.S. Sands, Y. Lifshitz, X. Shi, J. Appl. Phys. 87 (2000) 7283-7289.

[13] N.I. Maksimova, Technical University of Berlin, Ph.D. thesis, 2000. 